\title{
Enhancement of Sensorimotor Behavioral Recovery in Hemiparkinsonian Rats with Intrastriatal, Intranigral, and Intrasubthalamic Nucleus Dopaminergic Transplants
}

\author{
K. Mukhida, K. A. Baker, D. Sadi, and I. Mendez \\ Neural Transplantation Laboratory, Departments of Anatomy and Neurobiology and Surgery (Division of Neurosurgery), \\ Dalhousie University, Halifax, Nova Scotia, Canada B3H 4H7
}

\begin{abstract}
One of the critical variables that influences the efficacy of clinical neural transplantation for Parkinson's disease (PD) is optimal graft placement. The current transplantation paradigm that focuses on ectopic placement of fetal grafts in the striatum (ST) fails to reconstruct the basal ganglia circuitry or normalize neuronal activity in important basal ganglia structures, such as the substantia nigra (SN) and the subthalamic nucleus (STN). The aim of this study was to investigate a multitarget neural transplantation strategy for PD by assessing whether simultaneous dopaminergic transplants in the ST, SN, and STN induce functional recovery in hemiparkinsonian rats. Forty-six female Wistar rats with unilateral 6-hydroxydopamine lesions of the nigrostriatal pathway were randomly divided into eight groups and received lesions only or injections of 900,000 embryonic rat ventral mesencephalic cells in the (1) ST, (2) SN, (3) STN, (4) ST and SN, (5) ST, SN, and STN, (6) ST and STN, or (7) SN and STN. The number of cells transplanted was equally divided among grafting sites. Animals with two grafts received 450,000 cells in each structure, and animals with three grafts received
\end{abstract}

Since $1987,>200$ patients worldwide have received intrastriatal transplants of human fetal ventral mesencephalic tissue for the treatment of medically recalcitrant Parkinson's disease (PD) (Lindvall et al., 1989, 1990, 1992, 1994, 1998; Freed et al., 1992; Spencer et al., 1992; Widner et al., 1992; Freeman et al., 1995; Kordower et al., 1995, 1996; Wenning et al., 1997; Bluml et al., 1999; Hagell et al., 1999; Hauser et al., 1999; Mendez et al., 2000). Although the results of these trials have been promising, clinical efficacy has been limited and has not reached a level to justify the use of neural transplantation as a routine therapeutic procedure for PD.

One of the critical variables that influences the efficacy of clinical neural transplantation is optimal graft placement (Olanow et al., 1996; Mehta et al., 1997). The current experimental and clinical transplantation paradigm focuses on ectopic placement of fetal dopaminergic grafts in the striatum (ST) (Björklund et al., 1980, 1983; Dunnett et al., 1983; Freed et al., 1992; Mendez

\footnotetext{
Received Nov. 10, 2000; revised Feb. 23, 2001; accepted March 6, 2001.

This work was supported by the Dalhousie Medical Research Foundation Morris Kohler Studentship in Neuroscience to K.M. We acknowledge Ruperto Ulalia for his excellent technical assistance and Tanya Acorn for her assistance in the preparation of this manuscript.

Correspondence should be addressed to Dr. I. Mendez, Neural Transplantation Laboratory, Division of Neurosurgery, Department of Surgery, New Halifax Infirmary, Queen Elizabeth II Health Sciences Center, 1796 Summer Street, Room 3806, Halifax, Nova Scotia, Canada B3H 4H7. E-mail: mendez@is.dal.ca.

Copyright (C) 2001 Society for Neuroscience $0270-6474 / 01 / 213521-10 \$ 15.00 / 0$
}

300,000 cells per structure. Recovery was assessed by amphetamine-induced rotations and the stepping tests. Graft survival was assessed using tyrosine hydroxylase immunohistochemistry. At 8 weeks after transplantation, simultaneous dopaminergic transplants in the ST, SN, and STN induced significant improvement in rotational behavior and stepping test scores. Intrastriatal transplants were associated with significant recovery of rotational asymmetry, whereas SN and STN transplants were associated with improved forelimb function scores. These results suggest that restoration of dopaminergic activity to multiple basal ganglia targets, such as the ST and SN, or the ST and STN, promotes a more complete functional recovery of complex sensorimotor behaviors. A multitarget transplant strategy aimed at optimizing dopaminergic reinnervation of the basal ganglia may be crucial in improving clinical outcomes in PD patients.

Key words: subthalamic nucleus; dopamine; Parkinson's disease; neural transplantation; behavior; rat et al., 1992; Widner et al., 1992; Freeman et al., 1995). Animal studies have demonstrated that ectopically transplanted cells survive (Nishino, 1993), produce and secrete dopamine within the host ST (Schmidt et al., 1982; Nishino, 1993; Triarhou et al., 1994), attenuate amphetamine- and apomorphine-induced rotational asymmetry (Schmidt et al., 1982; Fisher and Gage, 1993), and establish synaptic connections with the host ST (Björklund and Stenevi, 1979; Mahalik et al., 1985; Doucet et al., 1989; Mendez et al., 1991; Nishino, 1993; Dunnett, 1995; Nikkhah et al., 1995). Clinical trials of neural transplantation have shown robust reinnervation of the ST as seen with positron emission tomography (Freeman et al., 1995; Remy et al., 1995; Wenning et al., 1997; Mendez et al., 2000) and postmortem studies (Kordower et al., 1995), as well as evidence of synaptic dopamine release as long as 10 years after transplantation (Piccini et al., 1999). However, intrastriatal grafts fail to reconstruct the dopaminergic basal ganglia circuitry that is affected in PD and do not reinnervate crucial basal ganglia structures such as the substantia nigra (SN) or subthalamic nucleus (STN). There is evidence from our laboratory that simultaneous dopaminergic reinnervation of the ST and SN (double grafts) may be superior to ST grafts alone (Mendez et al., 1996, 2000; Mendez and Hong, 1997; Baker et al., 2000). Furthermore, reinnervation of the $\mathrm{SN}$ in this double-graft strategy is required for improvement of complex sensorimotor behaviors such as the adjusting step test (Baker et al., 2000). Reinnervation of the STN by dopaminergic grafts may also be of 
benefit in functional recovery. There is recent evidence that upregulation of cytochrome oxidase and $c$-fos activity in the STN is not normalized in 6-hydroxydopamine (6-OHDA)-lesioned rats by intrastriatal grafts (Nakao et al., 1998). Failure to restore dopaminergic input to basal ganglia nuclei, such as the STN, may be an important factor limiting the efficacy of clinical transplantation for PD.

The STN is being increasingly recognized as having a central role in basal ganglia physiology and PD pathophysiology (Henderson and Dunnett, 1998). Decreased dopamine levels in the ST are thought to alter striatal function, including reduced activity of GABA/substance P/dynorphin medium spiny neurons and reduced inhibition of GABA/enkephalin medium spiny neurons, which render the globus pallidus pars externus (GPe) hypoactive by provoking excessive inhibition (Rodriguez et al., 1998). The excitatory tone of the STN consequently is left unbalanced (Rodriguez et al., 1998) and is thought to "drive" the output nuclei excessively (Starr et al., 1998). This model of PD is supported by data obtained using the 1-methyl-4-phenyl-1,2,3,6-tetrahydropyridine monkey model of PD in which metabolic activity and neuronal discharge frequency in the globus pallidus pars internus (GPi) and STN are increased compared with normal readings (Schwartzman et al., 1988; Bergman et al., 1990, 1994; Filion et al., 1991; Guridi et al., 1993; Starr et al., 1998). This excessive activity is thought to reduce indirectly the activity of the primary motor cortex, premotor cortex, and supplementary motor area (DeLong, 1990; Kumar et al., 1998a,b). Hassani and colleagues (1996) have demonstrated that this effect is attributable to more than just removal of pallidal inhibition and suggest that it may be explained by a decrease of intrinsic dopaminergic control of STN neuronal activity in PD. In this regard, reinnervation of the STN by dopaminergic transplants may be an appropriate therapeutic strategy for PD.

The present study is designed to investigate whether dopaminergic reinnervation of multiple basal ganglia target sites, such as the ST, SN, and STN, by ventral mesencephalic grafts can produce a more complete functional recovery in the rat model of PD. Behavioral recovery was assessed using the standard quantitative functional assessment of amphetamine-induced rotational asymmetry as well as more complex, non-drug-induced sensorimotor behavioral tests. The results of this study showed that simultaneous dopaminergic transplants in the ST and SN or the ST and STN induced significant improvement in rotational behavior and forelimb function as assessed by the adjusting step and initiation time tests. Intrastriatal transplants were associated with significant recovery of rotational asymmetry, whereas intranigral and intrasubthalamic nucleus transplants were associated with improved forelimb function scores. These observations suggest that an enhanced functional recovery in the rat model of PD is accomplished by reinnervation of the ST and SN or the ST and STN and suggest that a multiple target strategy may optimize neural transplantation for PD.

\section{MATERIALS AND METHODS}

\section{Animals and study design}

Forty-six female Wistar rats (Charles River, Saint Constant, Quebec) weighing 200-225 gm were used in this experiment. The rats were housed in pairs and allowed $7 \mathrm{~d}$ to acclimatize to the animal care facility before surgery or behavioral testing. They were kept in a room at constant temperature and humidity on a $12 \mathrm{hr}$ light/dark cycle. Animals were allowed ad libitum access to food and water when not undergoing surgery or behavioral testing. The experiments were conducted in accor-

\begin{tabular}{|c|c|}
\hline Week Number & Procedure \\
\hline 1 & $\begin{array}{l}\text { Habituation to Animal Care Facility } \\
\text { Training - stepping tests }\end{array}$ \\
\hline 2 & Baseline testing - stepping tests \\
\hline 4 & 6-OHDA lesions \\
\hline 6 & Post-lesion testing - rotation and stepping tests \\
\hline 7 & Transplantation \\
\hline 11 & $\begin{array}{l}\text { Post-transplantation testing - rotation and stepping } \\
\text { tests ( } 4 \text { weeks) }\end{array}$ \\
\hline 15 & $\begin{array}{l}\text { Post-transplantation testing - rotation and stepping } \\
\text { tests ( } 8 \text { weeks) }\end{array}$ \\
\hline 16 & Perfusion and immunohistochemistry \\
\hline
\end{tabular}

Figure 1. Timeline representing the sequence of procedures conducted during this experiment.

dance with the standards and procedures of the Canadian Council on Animal Care and the University Council on Laboratory Animals.

Hemiparkinsonism was induced in rats by lesioning the right nigrostriatal dopaminergic pathway with two stereotactic injections of 6-OHDA. The hemiparkinsonian rats were randomly assigned to one of eight treatment groups: one group received lesions only $(n=4)$, and the others received injections of 900,000 embryonic day 14 rat ventral mesencephalic cells in the (1) ST, (2) SN, (3) STN, (4) ST and SN, (5) ST, SN, and STN, (6) ST and STN, and (7) SN and STN ( $n=6$ for all groups). Functional recovery was assessed by using the amphetamine challenge and stepping tests after the lesions and after transplantation. The time course of this study, from the day on which the animals arrived until their brains were processed for tyrosine hydroxylase (TH) immunohistochemistry, is shown in Figure 1.

\section{6-OHDA lesions}

Rats received two stereotactic injections of 6-OHDA into the right ascending mesostriatal dopaminergic pathway via a metal cannula attached to a $10 \mu \mathrm{l}$ Hamilton microsyringe under a $3.0 \mathrm{ml} / \mathrm{kg}$ dose of ketamine-xylazine-acepromazine anesthetic mixture [25\% ketamine hydrochloride (MTC Pharmaceuticals, Cambridge, Ontario), $6 \%$ xylazine (Miles Canada, Etobicoke, Ontario), 2.5\% acepromazine maleate (Wyeth-Ayerst Canada, Montreal, Quebec) in $0.9 \%$ saline] at the following coordinates (in millimeters and with reference to bregma and the dura mater): (1) $2.5 \mu \mathrm{l}$ of 6-OHDA (3.6 $\mu \mathrm{g}$ 6-OHDA hydrogen bromide $/ \mu \mathrm{l}$ in $2.0 \mathrm{mg} / \mathrm{ml} \mathrm{L-ascorbate}$ in $0.9 \%$ saline) injected at anteroposterior (AP) -4.4, mediolateral (ML) -1.2, and dorsoventral (DV) -7.8, with the incisor bar set $2.4 \mathrm{~mm}$ below the interaural line (IA), and (2) 3.0 $\mu \mathrm{l}$ of $6-\mathrm{OHDA}$ injected at AP $-4.0, \mathrm{ML}-0.8$, and DV -8.0 , with the incisor bar set $3.4 \mathrm{~mm}$ above IA. The injection rate was $1 \mu \mathrm{l} / \mathrm{min}$, and the cannula was left in place for an additional $5 \mathrm{~min}$ before retraction. After a 2 week recovery period, the animals were given an amphetamine challenge $(5 \mathrm{mg} / \mathrm{kg}$, i.p.), and their rotation scores were collected over a 70 min period. Only animals that exhibited a mean ipsilateral rotation score of eight or more complete body turns per minute were included in the study.

\section{Transplantation}

Ventral mesencephalic tissue was harvested from embryonic day 14 Wistar rat fetuses removed from pregnant mothers anesthetized with a $3.0 \mathrm{ml} / \mathrm{kg}$ dose of a ketamine-xylazine-acepromazine anesthetic mixture. Fetal tissue was dissected in DMEM (Life Technologies, Gaithersburg, MD) and hibernated at $4^{\circ} \mathrm{C}$ in $10 \mathrm{ml}$ of a low-sodium, phosphatebuffered, calcium-free hibernation medium containing (in mM): $30 \mathrm{KCl}$, 5.0 glucose, $0.24 \mathrm{MgCl}_{2}, 10.95 \mathrm{NaH}_{2} \mathrm{PO}_{4}, 5.0 \mathrm{Na}_{2} \mathrm{HPO}_{4}, 20$ lactic acid, $32.18 \mathrm{KOH}$, and 164.7 sorbitol, $\mathrm{pH}$ 7.4. The hibernation medium was changed daily, and after $5 \mathrm{~d}$ fetal ventral mesencephalic (FVM) cell suspensions were made by first rinsing the tissues three times in $0.05 \%$ 


\begin{tabular}{|c|c|c|c|c|c|c|}
\hline \multirow[b]{2}{*}{ Group } & \multirow[b]{2}{*}{$n$} & \multicolumn{3}{|c|}{ Coordinates } & \multirow{2}{*}{$\begin{array}{l}\text { Total graft } \\
\text { volume }(\mu \mathrm{l})\end{array}$} & \multirow{2}{*}{$\begin{array}{l}\text { Total number } \\
\text { of cells }\end{array}$} \\
\hline & & AP & $\mathrm{L}$ & V & & \\
\hline \multirow[t]{3}{*}{ ST } & 6 & +1.3 & -2.1 & -5.5 and -4.3 & 3 & 900,000 \\
\hline & & +0.6 & -2.9 & -5.5 and -4.3 & & \\
\hline & & +0.3 & -3.7 & -5.5 and -4.3 & & \\
\hline \multirow[t]{3}{*}{$\mathrm{SN}$} & 6 & -4.8 & -2.0 & -8.3 and -8.1 & 3 & 900,000 \\
\hline & & -5.0 & -2.3 & -8.2 and -8.0 & & \\
\hline & & -5.3 & -2.6 & -8.1 and -7.9 & & \\
\hline \multirow[t]{2}{*}{ STN } & 6 & -3.8 & -2.6 & -8.0 & 3 & 900,000 \\
\hline & & -3.8 & -2.2 & -8.2 & & \\
\hline ST and SN & 6 & \multicolumn{3}{|c|}{ Same coordinates as for striatal and nigral grafts } & 3 & 450,000 per site \\
\hline ST and STN & 6 & \multicolumn{3}{|c|}{ Same coordinates as for striatal and subthalamic grafts } & 3 & 450,000 per site \\
\hline SN and STN & 6 & \multicolumn{3}{|c|}{ Same coordinates as for nigral and subthalamic grafts } & 3 & 450,000 per site \\
\hline ST, SN, and STN & 6 & \multicolumn{3}{|c|}{ Same coordinates as for striatal, nigral, and subthalamic grafts } & 3 & 300,000 per site \\
\hline
\end{tabular}

DNase (Sigma, St. Louis, MO)/DMEM and then incubating them in $0.1 \%$ trypsin (Worthington, Freehold, NJ) $/ 0.05 \%$ DNase/DMEM at $37^{\circ} \mathrm{C}$ for $20 \mathrm{~min}$. The tissues were subsequently rinsed four times in $0.05 \%$ DNase/DMEM and mechanically dissociated using a $1 \mathrm{ml}$ and then a $200 \mu l$ Eppendorf pipetter until a uniform cell suspension was made. The tissue was centrifuged at 600 rotations per minute for $5 \mathrm{~min}$, the supernatant was discarded, and the pellet was suspended in $0.05 \%$ DNase/DMEM. The trypan blue dye exclusion method was used to ascertain the viability and relative concentration of cells in suspension. A final cell concentration of $\sim 30,000$ cells $/ \mu l$ was used, with viability exceeding $98 \%$. A total of $\sim 900,000$ cells were stereotactically transplanted in hemiparkinsonian animals using a glass microcapillary with an outer opening diameter of between 50 and $70 \mu \mathrm{m}$ attached to a $2 \mu \mathrm{l}$ Hamilton microsyringe. The stereotactic coordinates are presented in Table 1.

\section{Behavioral assessment}

Rotational behavior. Rats were challenged with amphetamine $(5 \mathrm{mg} / \mathrm{kg}$, i.p.) 2 weeks after lesions and 4 and 8 weeks after transplantation. Rotational behavior was monitored for 70 min using a computerized video activity monitor system (Videomex, Columbus Instruments, Columbus, $\mathrm{OH}$ ).

Sensorimotor testing. The adjusting step and initiation time components of the stepping tests were used in this study, as described by Olsson and colleagues (1995). All of the behavioral tests were conducted by the same investigator in a consistent manner in terms of technique and time of testing; the stepping test was performed between 8:00 A.M. and 4 P.M. The animals were trained in these tests once per day for 2 weeks and were tested before 6-OHDA lesions, 3 weeks after lesion, and 4 and 8 weeks after transplantation. The adjusting step and initiation time components of the stepping test were used to assess forelimb function and the motivational component of akinesia, respectively. The adjusting step test involved immobilizing the hindlimbs and one forelimb as the rats were moved slowly across a $0.9 \mathrm{~m}$ wooden plank. Each forelimb was tested three times during a test session. The total number of adjusting steps that the animals made with their free forelimb to maintain balance in both the backhand and forehand directions was recorded. The initiation time component of the test involved attaching the wooden ramp to the animals' home cage, holding the animals in a similar manner as in the adjusting step test, and determining the time, for each forelimb, that the animals required to initiate movement up the ramp to their cage. Each forelimb was tested three times during a test session.

\section{Immunohistochemistry}

Nine weeks after transplantation, the rats were deeply anesthetized with $4.5 \mathrm{ml} / \mathrm{kg}$ of ketamine-xylazine-acepromazine mixture and perfused transcardially with $250 \mathrm{ml}$ of cold $0.1 \mathrm{M}$ phosphate buffer (PB), $\mathrm{pH}$ 7.4, followed by $250 \mathrm{ml}$ of ice-cold $4 \%$ paraformaldehyde in $0.1 \mathrm{M} \mathrm{PB}$, and then cryoprotected in $30 \%$ sucrose in $\mathrm{PB}$ at $4^{\circ} \mathrm{C}$ until the brains were completely submerged. Coronal sections $(40 \mu \mathrm{m})$ were cut serially on a
Leitz freezing microtome from the genu of the corpus callosum to the caudal end of the SN and placed in $0.1 \mathrm{M}$ PB.

Tyrosine hydroxylase immunohistochemistry was performed on every fourth section for analysis of FVM graft viability within the STN. Standard ABC methodology was used. Briefly, the selected sections were rinsed twice for $5 \mathrm{~min}$ each time in $0.1 \mathrm{M} \mathrm{PB}$ and then washed for $10 \mathrm{~min}$ in $3 \% \mathrm{H}_{2} \mathrm{O}_{2}$ and $10 \%$ methanol in $0.1 \mathrm{M} \mathrm{PB}$. After three 5 min rinses in $0.1 \mathrm{M} \mathrm{PB}$, sections were treated for $1 \mathrm{hr}$ in $5 \%$ normal swine serum (NSS) and $0.3 \%$ Triton X-100 in $0.1 \mathrm{M} \mathrm{PB}$, and then incubated for $16 \mathrm{hr}$ in 1:2500 rabbit polyclonal anti-TH antibody (Pel-Freez Biologicals, Rogers, AR) $/ 5 \%$ NSS $/ 0.3 \%$ Triton X-100 in 0.1 M PB. Subsequent to incubation, sections were washed three times for 5 min each time in $0.1 \mathrm{M} \mathrm{PB}$ and then incubated for $1 \mathrm{hr}$ in 1:500 biotinylated swine anti-rabbit immunoglobulin antibody (Dako, Carpinteria, CA)/0.3\% Triton X-100 in $0.1 \mathrm{M} \mathrm{PB}$, and then, after the sections were washed in $0.1 \mathrm{M} \mathrm{PB}$, they were incubated for $1 \mathrm{hr}$ in 1:200 avidin and 1:200 biotin (ABC kit, Vector Laboratories Canada, Burlington, Ontario) in 0.1 M PB. Peroxidase activity was developed using 3,3-diaminobenzidine dissolved in $0.1 \mathrm{M} \mathrm{PB}$ and $1 \% \mathrm{H}_{2} \mathrm{O}_{2}$. Sections were rinsed in $0.1 \mathrm{M} \mathrm{PB}$ and then mounted on gelatin-coated slides and air dried overnight. The slides were dehydrated in an ethanol to xylene series and coverslipped with Permount.

\section{Cell counts}

The total number of surviving transplanted TH-immunoreactive (IR) cells in the grafts was estimated by using a $10 \times 10 \mathrm{~mm}$ ocular lens grid. Profile counts were done on every fourth section containing grafted cells by an observer blinded to identity of the sections. An approximation of the final grafted cell number was estimated by using Abercrombie's (1946) formula, $P=(1 / f) A M /(D+M)$, where $P$ is the corrected number of TH-immunoreactive cell profiles in the grafts, $f$ is the frequency of sections selected for immunocytochemistry and analysis, $A$ is the raw count of the cell profiles, $M$ is the section thickness in micrometers, and $D$ is the average cell profile diameter in micrometers. The total number of cell profiles was averaged to give an estimate of the total number of TH-immunoreactive cell profiles for each transplant treatment group. Profile cell diameters were determined by (1) randomly picking one graft deposit from each section and (2) randomly picking three THimmunoreactive cell profiles from that deposit. The longest and shortest diameters of each profile were measured using an ocular micrometer and averaged to give the average profile diameter.

\section{Statistical analyses}

The rotational and stepping test scores before and after transplantation were assessed for within and between group differences at $p<0.05$ using a two-way ANOVA and Tukey's post hoc test. The statistical analysis for cell counts was conducted using a two-way ANOVA followed by Tukey's post hoc test. 

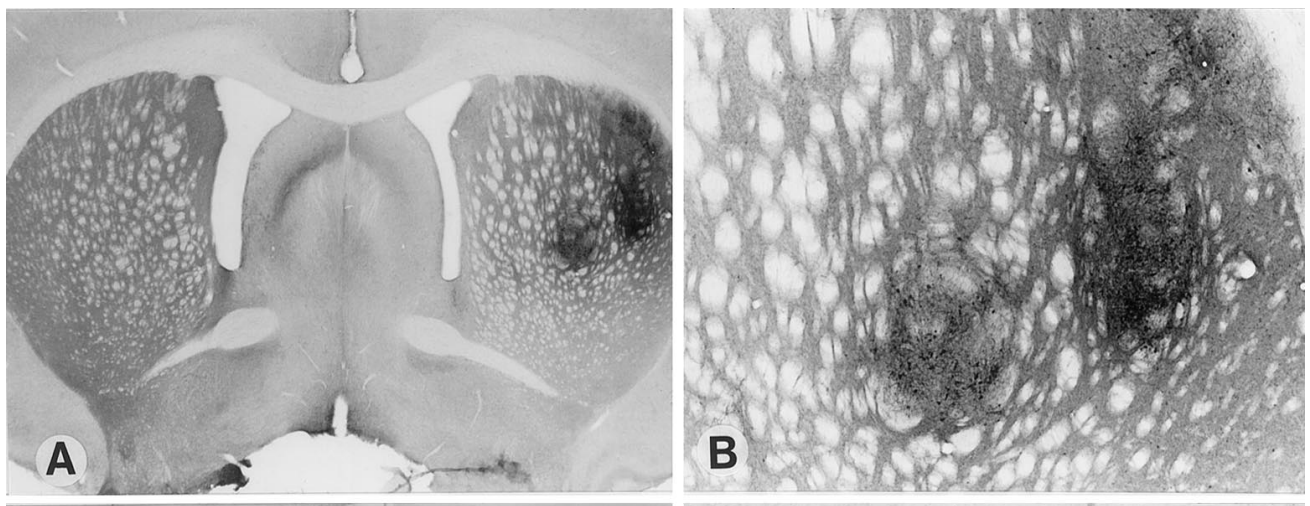

Figure 2. Representative TH-immunostained coronal tissue sections of a rat striatum $(A)$, substantia nigra $(C)$, and subthalamic nucleus $(E)$ transplanted with FVM cell suspension. $B, D$, and $F$ represent high-power views of the grafts. Scale bar (shown in $F$ ): $A, C, E, 1000$ $\mu \mathrm{m} ; B, D, F, 400 \mu \mathrm{m}$.
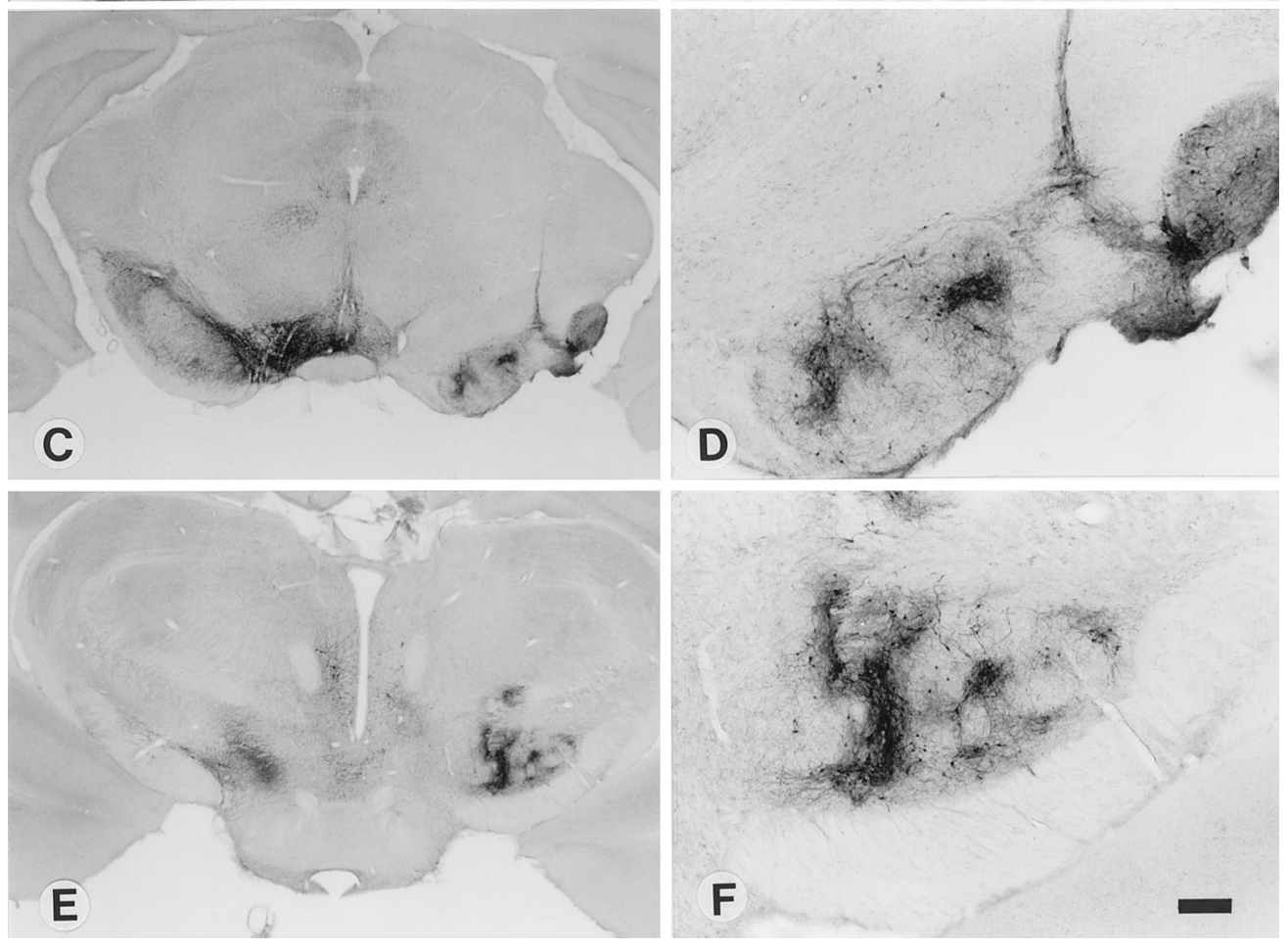

\section{RESULTS \\ 6-OHDA lesions}

The injections of 6-OHDA into the right ascending mesostriatal dopaminergic pathway resulted in the virtual elimination of $\mathrm{TH}$ immunoreactivity in the ispilateral ST, SN, and STN. At the level of the more rostral sections of the SN (IA $4.20 \mathrm{~mm}$, bregma -4.8 $\mathrm{mm}$ ) no TH-IR cells were visualized in the SN pars compacta (SNc) and pars reticulata (SNr), ventral tegmental area (VTA), and medial forebrain bundle (MFB). TH-IR cells were observed around the third ventricle and the periventricular fiber system down to the supramamillary nucleus. At the level of the most caudal sections of the SN (bregma -5.80 and bregma -6.04), TH-IR cells were absent in the SNc, SNr, VTA, and MFB. TH-IR cells were present only in the dorsomedial interpeduncular nucleus. The STN ipsilateral to the lesion was devoid of any TH immunoreactivity.

In contrast, the SN, STN, and ST contralateral to the 6-OHDA injections were characterized by extensive and dense TH-IR (Fig. $2 A, C, E)$. TH-IR cells were observed immediately adjacent to the cerebral aqueduct and third ventricle, as well as along the midline to the supramamillary nucleus and in the dorsal tegmental decussation and the caudal linear nucleus of raphe. Dense $\mathrm{TH}$ immunoreactivity was visualized in the SNc, VTA, and MFB, as well as throughout the ST, with the densest neuropil on the perimeter of the ST adjacent to the left lateral ventricle, corpus callosum, and cerebral cortex.

\section{Transplants}

All animals that received transplants of FVM cell suspensions demonstrated viable grafts at 9 weeks after transplantation that were composed of numerous TH-IR cell bodies and fibers (Fig. 2). Animals that received intrastriatal transplants showed that the grafts restored some of the TH-IR neuropil that was lost because of the 6-OHDA nigral lesions (Figs. $2 A, B, 3 A, B$ ). The neuropil was restricted to the $\mathrm{ST}$ and did not extend into the cerebral cortex or corpus callosum. Up to three deposits of cells were observed in the ST, and most deposits had a round shape in coronal and sagittal section. Some were tear-drop shaped, presumably because the TH-IR neurons followed the glass capillary tract when the capillary was retracted from the brain parenchyma. TH-IR neurons were visualized throughout the grafts in clusters. Numerous neuritic processes emanated from the transplanted cells and extended throughout the graft as well as for variable 

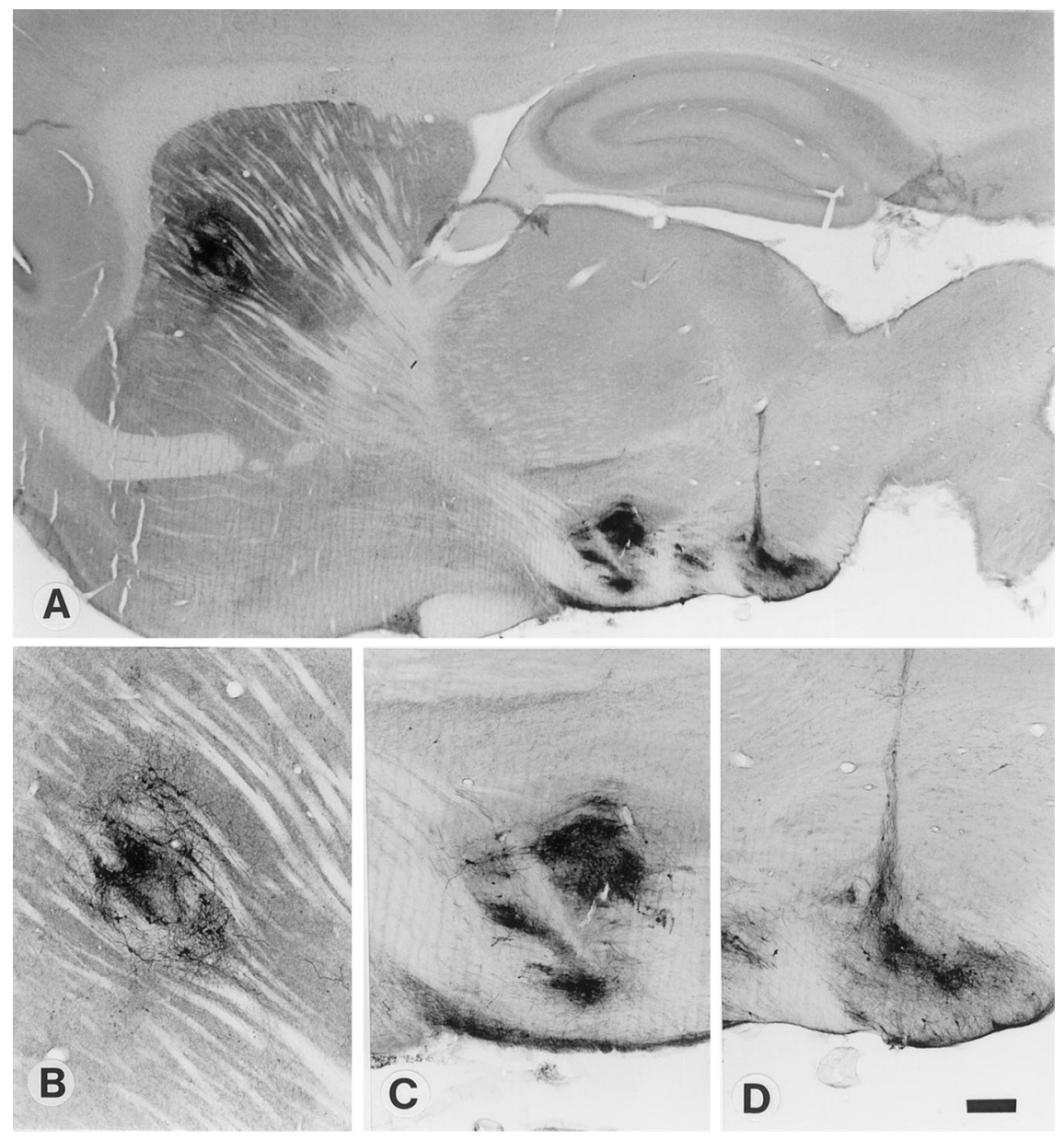

Figure 3. A, Representative sagittal section of a rat brain transplanted with simultaneous intrastriatal, intranigral, and intrasubthalamic nucleus dopaminergic cell suspensions. Dense TH-IR areas representing the grafts are seen in the ST, SN, and STN. B, High-power view of the intrastriatal graft. $C$, High-power view of the intrasubthalamic nucleus transplants. $D$, Highpower view of the intranigral transplants. Scale bar (shown in $D$ ): $A, 1000 \mu \mathrm{m} ; B, C, D, 400 \mu \mathrm{m}$.

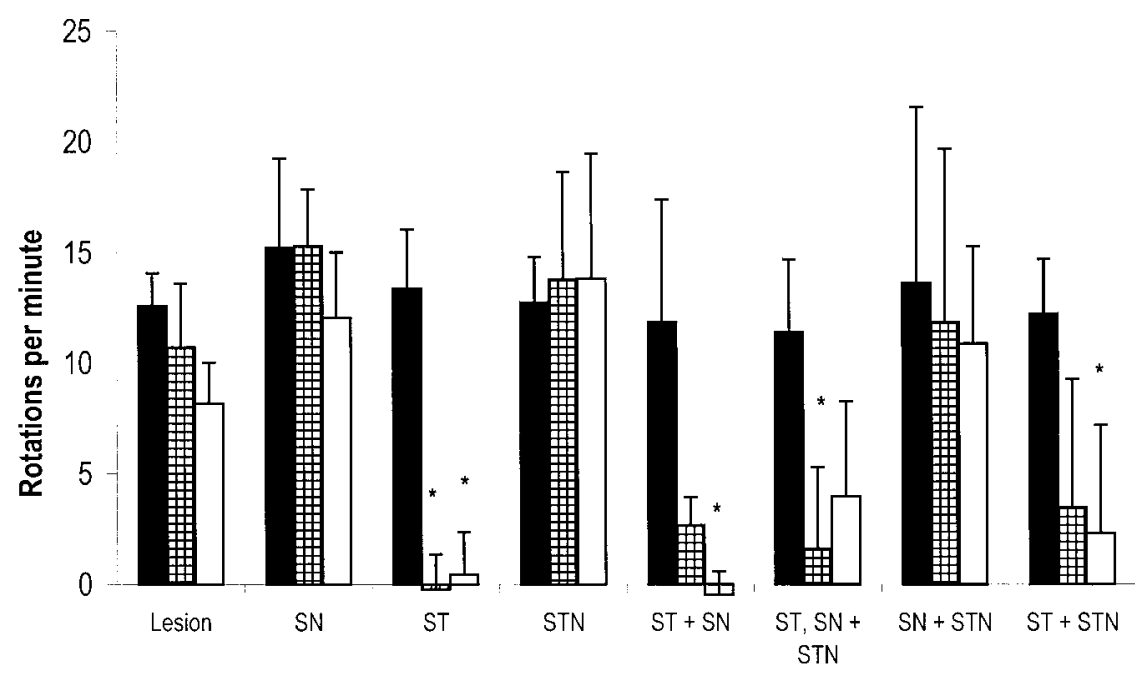

Treatment groups
Figure 4. Rotational behavior of rats after lesion (black bars) and 4 (striped bars) and 8 weeks after transplantation (white bars) of fetal ventral mesencephalic cells. Each bar represents the mean + SD rotations per minute; ${ }^{*} p<0.05$ compared with rotational scores after lesion. distances into the host brain. Intranigral grafts were well circumscribed to the SN (Figs. 2C,D, 3D), although some animals demonstrated clusters of cells positioned along the capillary tracts. The grafts recapitulated the normal nigral architecture, with more dense clusters of TH-IR cells lying superior to less dense areas. The intrasubthalamic nucleus grafts were similarly well localized within the STN (Figs $2 E, F$ ). In animals that received intranigral or intrasubthalamic nucleus grafts alone, few fibers were seen to project rostrally toward the internal capsule or MFB. Animals that received simultaneous intrastriatal, intranigral, and intrasubthalamic nucleus grafts also demonstrated surviving grafts with dense clusters of cells and fibers (Fig. 3). 


\section{Right Forelimb Initiation Time}

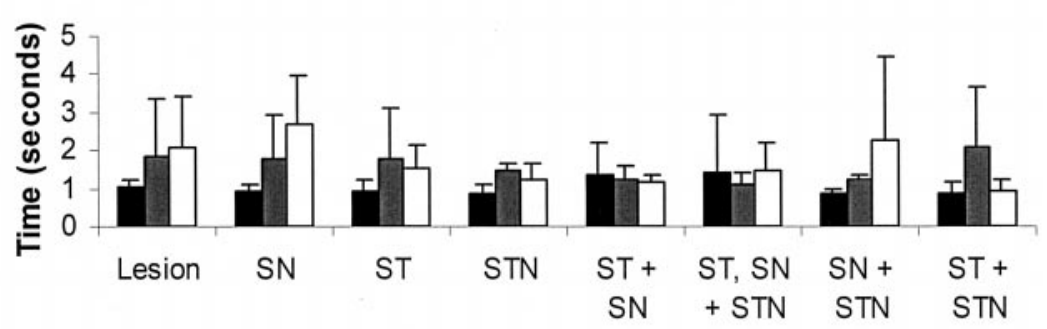

Treatment group

Figure 5. Right and left forelimb initiation times for the stepping test before 6-OHDA lesions (black bars), after lesion (gray bars), and 8 weeks after transplantation (white bars). Each bar represents the mean + SD scores for initiation time; ${ }^{*} p<0.05$ compared with scores for the lesion-only group 8 weeks after transplantation; ${ }^{* *} p<0.05$ compared with scores before lesions.

\section{Behavioral studies \\ Rotational behavior}

There was no significant difference in the number of amphetamine-induced ipsiversive rotations in animals before transplantation between each group (Fig. 4). Control rats that were not transplanted with cells showed no attenuation of this behavior over the course of the experiment. Similarly, animals that received grafts in the SN alone, the STN alone, or in both the SN and STN showed no significant improvement of rotation scores $(p>0.05)$. All animals that were transplanted in the ST, either alone or simultaneously in other structures, demonstrated significant rotational improvement compared with pretransplant scores $(p<0.05)$. At 8 weeks after transplantation, animals that received simultaneous FVM transplants in the ST and SN rotated contraversive to the lesion. This contraversive rotation was not statistically significant and was also not observed in any other treatment group. Although animals with grafts in the ST, SN, and STN showed a decrease in rotations by 8 weeks after transplantation, this decrease did not reach statistical significance $(p>$ $0.05)$.

\section{Stepping test}

The initiation time test revealed that all animals were able to initiate movement up the ramp attached to the home cage with either forelimb immediately after positioning at the base of the ramp (Fig. 5). There was no significant difference in these times between right and left forelimbs or between treatment groups. Animals were able to initiate movement with the right forelimb between $0.84 \pm 0.16$ and $1.39 \pm 1.56 \mathrm{sec}$ and with the left forelimb between $0.70 \pm 0.13$ and $1.48 \pm 1.54 \mathrm{sec}$. After 6-OHDA lesions, all animals demonstrated a statistically significant increase in initiation times for the left forelimb $(p<0.05)$ but no significant effect on scores for the right forelimb $(p>0.05)$. This increase varied from $6.03 \pm 4.07 \mathrm{sec}$ to as much as $20.92 \pm 23.05 \mathrm{sec}$. By 8 weeks after transplantation, animals that received transplants in the SN or STN demonstrated a statistically significant reduction of initiation time scores compared with scores for the lesion-only group $(p<0.05)$. There was almost complete normalization of these scores for the animals that received transplants simultaneously in the ST, SN, and STN or simultaneously in the SN and STN; their scores decreased to $2.16 \pm 1.07$ and $1.90 \pm 0.46 \mathrm{sec}$, respectively. Animals that received intrastriatal FVM transplants showed some decrease in scores, with a mean score of $11.21 \pm$ $13.28 \mathrm{sec}$ by 8 weeks, but this was not statistically significant.

All animals demonstrated no significant bias in the number of adjusting steps that they were able to make with either forelimb before the lesioning procedure, and there were no significant differences between groups in the number of steps the animals made (Fig. 6). On average, the animals made $24.56 \pm 0.98$ steps with the right forelimb and $23.52 \pm 1.62$ steps with the left forelimb. After lesioning, the number of steps that the animals made with the left forelimb significantly decreased $(p<0.05)$. The animals were observed to drag the left forelimb along the wooden plank in both the forehand and backhand directions, with a lack of coordinated movement. The number of steps decreased significantly in all groups to an average of $4.11 \pm 1.68$ for the left forelimb. The number of steps made by the right forelimb was unaffected by the lesions or the transplants. By 8 weeks after transplantation, all treatment groups demonstrated an increase in the number of adjusting steps made by the left forelimb, but this reached statistical significance only for those animals that received FVM cell transplants simultaneously in the ST, SN, and 
Right Forelimb Adjusting Steps

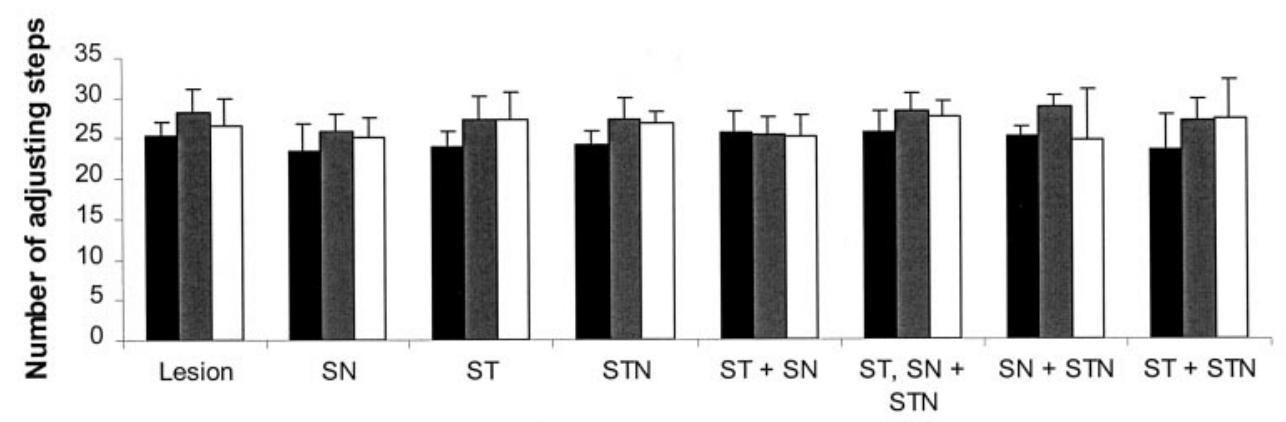

Treatment group

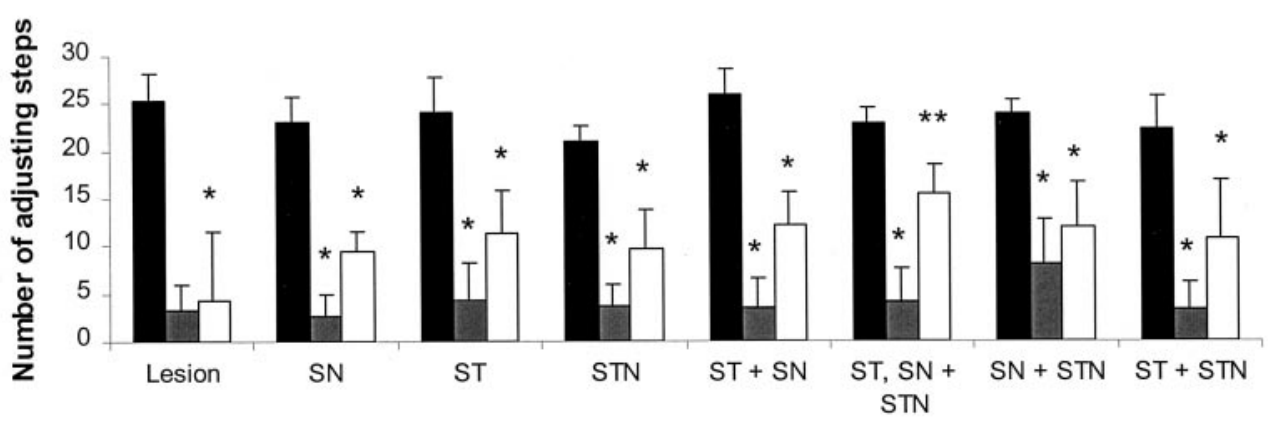

Treatment group
Figure 6. Right and left adjusting step scores for the stepping test before 6-OHDA lesions (black bars), after lesion ( gray bars), and 8 weeks after transplantation (white bars). Each bar represents the mean + SD adjusting step scores. ${ }^{* *} p<0.0002$ compared with scores after lesion; * $p<0.01$ compared with scores before lesion.
STN $(p<0.05)$. The number of steps these animals made increased to $15.50 \pm 3.07$. Of note, the number of steps that the animals made with grafts in the ST and SN almost reached statistical significance at 8 weeks after transplantation at $p<0.06$ when compared with the scores after lesion.

\section{Cell counts}

The number of surviving transplanted TH-immunoreactive cells was determined for animals that received grafts in the ST alone or in combination with grafts in the SN or STN. The mean $( \pm S D)$ number of TH-immunoreactive cells within the grafts in these four groups were as follows: $\mathrm{ST}=1781 \pm 431$; $\mathrm{ST}$ and $\mathrm{SN}=$ $1700 \pm 733 ;$ ST and STN $=2044 \pm 1028$; and ST, SN, and STN = $1743 \pm 847$. There was no significant difference in the total number of surviving cells between those treatment groups.

\section{DISCUSSION}

The ST has been the main target of current neural transplantation strategies for PD (Björklund et al., 1980, 1983; Dunnett et al., 1983; Lindvall et al., 1989; Mendez et al., 1991; Freed et al., 1992; Widner et al., 1992; Freeman et al., 1995). Although striatal dopaminergic transplants can reinnervate the ST, they fail to reinnervate other basal ganglia structures. We have previously adopted a "double grafting" strategy by targeting both the ST and SN with dopaminergic grafts (Mendez et al., 1996; Mendez and Hong, 1997; Baker et al., 2000). In an effort to further explore basal ganglia reinnervation and functional recovery by dopaminergic grafts, we have investigated a multitarget grafting approach to reinnervate the ST, SN, and STN in hemiparkinsonian rats. The present study has shown for the first time that dopaminergic grafts can survive and reinnervate the STN. Furthermore, the results suggest that a multitarget grafting strategy aimed at increasing basal ganglia dopaminergic reinnervation may enhance recovery of complex sensorimotor behaviors in the rat model of PD.

The STN is an appropriate target for neural transplantation because of its central role in basal ganglia physiology and PD pathophysiology. According to the current model of basal ganglia physiology, the STN participates in the "indirect" output pathway of the ST by receiving GABAergic input from the GPe and providing glutamatergic output to the $\mathrm{SNr}$ and GPi. Thalamocortical disinhibition is thought to result from lesions of the STN, which produces hemiballismus (Hamada and DeLong, 1992; Vidakovic et al., 1994; Albin et al., 1995). The STN has been observed to be overactive in animal models of PD (Bergman et al., 1994; Hassani et al., 1996; Nakao et al., 1998). However, Henderson and Dunnett (1998) have questioned the prediction of this model of STN hyperactivity as a result of Parkinsonianinduced GPe disinhibition. They suggest that the reception by the STN of excitatory inputs from the cortex and center medianparafascicular complex of the thalamus and inhibitory inputs from the $\mathrm{SN}$ and tegmentum make it possible that PD involves hyperactivity of the STN because of excessive excitatory cortical and parafascicular thalamic input and decreased inhibitory nigral and tegmental input to the STN.

Targeting the STN with dopaminergic grafts may be important because there is evidence of a direct role for dopamine in the STN. The STN is known to be innervated by dopaminergic SNc neurons (Lavoie et al., 1989; Hassani et al., 1997; Cossette et al., 1999; Hedreen, 1999, François et al., 2000). The presence of varicose dopamine terminals (Brown et al., 1979; Hauber, 1998) and direct dopaminergic input from the SN (Versteeg et al., 1976; Campbell et al., 1985; Flores et al., 1999) in the STN suggests a dopaminergic influence on neuronal activity. Flores and col- 
leagues (1999) have studied the expression of dopamine receptor subtypes in the STN and their pharmacological characteristics and found D1, D2, and D3 receptor messenger ribonucleic acids and binding sites and D4 receptor binding sites in the STN of normal rats. Induction of hemiparkinsonism in the animals with 6-OHDA did not change D1 receptor levels, increased D2 receptor levels, and decreased D3 receptor levels in the STN, suggesting that STN dopamine receptors play an important role in basal ganglia physiology because D1, D2, or D3 receptors may mediate the effects of dopamine on STN neural activity, and D4 receptors may mediate presynaptic effects exclusively (Flores et al., 1999). Hauber (1998) also emphasizes the role of D1 receptors in the contributions of STN to motor function by demonstrating that selective blockade of those receptors with the antagonist $\mathrm{SCH}$ 23390 produces catalepsy. Electrophysiological (Campbell et al., 1985; Mintz et al., 1986) and 2-deoxyglucose studies (Wolfson et al., 1982; Trugman, 1995) have also suggested the responsiveness of STN neurons to dopamine.

Restoration of dopaminergic input to multiple basal ganglia targets, including the STN, may optimize recovery of 6-OHDAinduced behavioral deficits. When amphetamine-induced turning behavior was analyzed, animals with FVM grafts in the SN or STN, or both, demonstrated no rotational compensation. This lack of compensation has been noted previously with dopaminergic grafts in the SN (Nikkhah et al., 1994; Mendez et al., 1996) and could be related to the inability of grafts in the STN or SN to release dopamine in the ST. The present study confirms the notion that dopaminergic reinnervation of the ST is necessary to restore rotational symmetry in the 6-OHDA rodent model of PD. However, the decrease in rotations in animals that received ST grafts of 300,000 cells (ST, SN, and STN transplantation group) did not reach statistical significance at 8 weeks after transplantation. This observation suggests that 300,000 cells were insufficient to reinnervate the ST and maintain the significant decrease in rotations observed at 4 weeks after transplantation. It is clear from this and previous studies that ST grafts of at least 400,000 cells are required to achieve restoration of rotational symmetry when the SN or STN are also targeted (Mendez et al., 1996; Baker et al., 2000). As has been shown in a previous study (Mendez et al., 1996), grafting both the SN and ST produces overcompensation with contralateral rotations by 6 weeks after transplantation. Although the mechanism of this overcompensation is not clear, it has been suggested that amphetamine-dependent dopamine release is higher in the transplant side than in the contralateral intact side (Forni et al., 1989).

Although rotational behavior has been used as the main test for functional recovery after transplantation, it lacks correlation to the complex sensorimotor deficits experienced by patients with PD. The adjusting step and initiation time tests correlate better with the human condition. The results of the stepping tests suggest that improvements in forelimb function and the motivational component of akinesia may be more dependent on restoring dopaminergic input to the SN and STN than to the ST. The adjusting step test has been correlated to the limb akinesia demonstrated by Parkinsonian patients. This study demonstrates that restoration of dopaminergic reinnervation to the $\mathrm{SN}$ and STN may be required to improve performance in these tests. Animals that received simultaneous ST, SN, and STN grafts significantly attenuated their adjusting step deficit. Animals with simultaneous ST and SN grafts also showed improvement, but this minimally missed reaching statistical significance $(p<0.06)$. These functional effects may be related to the location of the grafts and not to differences in grafted cell survival between the treatment groups, because there was no significant difference in the number of surviving grafted TH-immunoreactive cells between the groups that had grafts in the striatum only or in combination with one or both of the other target sites. Our laboratory has previously demonstrated that these double grafts can induce significant improvement in this test (Baker et al., 2000). The results of the initiation time test revealed that dopaminergic transplants in the SN or STN alone, or in combination with any of the other sites, ameliorated the animals' deficits after lesion. In contrast, striatal transplants did not produce such improvement. It has been postulated that this may be because of the inability of intrastriatal transplants alone to reinnervate the SN and STN and reconstitute the dopaminergic basal ganglia circuitry (Mehta et al., 1997; Baker et al., 2000). This notion is supported by a recent study in which cytochrome oxidase activity in several basal ganglia structures was quantified after intrastriatal dopaminergic transplantation in hemiparkinsonian rats (Nakao et al., 1998). The STN remained overactive after transplantation, and the authors concluded that the striatal grafts failed to influence this structure. It has been suggested previously that dopamine primarily reduces the discharge rate and c-fos expression in STN neurons (Campbell et al., 1985; Hassani and Féger, 1999). Thus, restoring dopaminergic input to the STN may be important for reducing its activity and producing enhanced functional recovery.

A multitarget grafting strategy may be necessary to optimize dopaminergic reinnervation of the basal ganglia. It is clear that intrastriatal grafts alone fail to provide complete functional recovery in animal models of PD even if strategies are used to distribute multiple microtransplants over larger areas of the ST (Winkler et al., 1999), increase striatal reinnervation (Winkler et al., 1999), or increase the number of transplanted cells (Mehta et al., 1998). The present investigation suggests that dopamine target regions other than the ST may have to be reached to influence more complex aspects of dopamine-dependent behaviors.

\section{Concluding remarks}

The results of this study suggest that a multitarget grafting strategy aimed at restoring dopaminergic reinnervation to the ST, SN, and STN may be necessary to optimize functional recovery in the rat model of PD. Although reinnervating the ST appears to be important for restoring rotational symmetry, improvement of more complex sensorimotor behaviors, such as the adjusting step and initiation time, may depend on reinnervation of the $\mathrm{SN}$ or STN, or both. Finding the appropriate targets for transplantation in Parkinsonian patients is of critical importance to optimize clinical outcomes.

\section{REFERENCES}

Abercrombie M (1946) Estimation of nuclear population from microtome sections. Anat Rec 94:239-247.

Albin RL, Young AB, Penney JB (1995) The functional anatomy of disorders of the basal ganglia. Trends Neurosci 18:63-64.

Baker KA, Sadi D, Hong M, Mendez I (2000) Simultaneous intrastriatal and intranigral dopaminergic grafts in the parkinsonian rat model: role of the intranigral graft. J Comp Neurol 426:106-116.

Bergman H, Wichmann T, DeLong MR (1990) Reversal of experimental parkinsonism by lesions of the subthalamic nucleus. Science 249:1436-1438.

Bergman H, Wichmann T, Karmon B, Delong MR (1994) The primate subthalamic nucleus. II. Neuronal activity in the MPTP model of parkinsonism. J Neurophysiol 72:507-520.

Björklund A, Stenevi U (1979) Reconstruction of the nigrostriatal dopamine pathway by intracerebral nigral transplants. Brain Res 177:555-560.

Björklund A, Dunnett SB, Stenevi U, Lewis ME, Iversen SD (1980) Reinnervation of the denervated striatum by substantia nigra trans- 
plants: functional consequences as revealed by pharmacological and sensorimotor testing. Brain Res 199:307-333.

Björklund A, Stenevi U, Schmidt RH, Dunnett SB, Gage FH (1983) Intracerebral grafting of neuronal cell suspensions. II. Survival and growth of nigral cell suspensions implanted in different brain sites. Acta Physiol Scand [Suppl] 522:9-18.

Bluml S, Kopyov O, Jacques S, Ross BD (1999) Activation of neural transplants in humans. Exp Neurol 158:121-125.

Brown L, Makman MH, Wolfson LI, Dvorkin B, Warner C, Katzman R (1979) A direct role of dopamine in the rat subthalamic nucleus and adjacent intrapeduncular area. Science 206:1416-1418.

Campbell GA, Eckardt MJ, Weight FF (1985) Dopaminergic mechanisms in the subthalamic nucleus of rat: analysis using horseradish peroxidase and microiontophoresis. Brain Res 333:261-270.

Cossette M, Levesque M, Parent A (1999) Extrastriatal dopaminergic innervation of human basal ganglia. Neurosci Res 34:51-54.

DeLong MR (1990) Primate models of movement disorders of basal ganglia origin. Trends Neurosci 13:281-285.

Doucet G, Murata Y, Brundin P, Bosler O, Mons N, Geffard M, Ouimet CC, Björklund A (1989) Host afferents into intrastriatal transplants of fetal ventral mesencephalon. Exp Neurol 106:1-19.

Dunnett SB (1995) Functional repair of striatal systems by neural transplants: evidence for circuit reconstruction. Behav Brain Res 66:133-142.

Dunnett SB, Björklund A, Schmidt RH, Steveni U, Gage FH (1983) Intracerebral grafting of neuronal cell suspensions. IV. Behavioural recovery in rats with unilateral 6-OHDA lesions after implantation of nigral cell suspensions in different forebrain sites. Acta Physiol Scand [Suppl] 522:29-37.

Filion M, Tremblay L, Bedard PJ (1991) Effects of dopamine agonists on the spontaneous activity of globus pallidus neurons in monkeys with MPTP-induced parkinsonism. Brain Res 547:152-161.

Fisher LJ, Gage FH (1993) Grafting in the mammalian central nervous system. Physiol Rev 73:583-616.

Flores G, Liang LL, Sierra A, Martínez-Fong D, Quirion R, Aceves J, Srivastava LK (1999) Expression of dopamine receptors in the subthalamic nucleus of the rat: characterization using reverse transcriptase-polymerase chain reaction and autoradiography. Neuroscience 91:549-556.

Forni C, Brundin P, Stricker EM, El Ganouni S, Björklund A, Nieoullon A (1989) Time-course of recovery of dopamine neuron activity during reinnervation of the denervated striatum by fetal mesencephalic grafts as assessed by in vivo voltammetry. Exp Brain Res 76:75-87.

François C, Savy C, Jan C, Tande D, Hirsch EC, Yelnik J (2000) Dopaminergic innervation of the subthalamic nucleus in the normal state, in MPTP-treated monkeys, and in Parkinson's disease patients. J Comp Neurol 425:121-129.

Freed CR, Breeze RE, Rosenberg NL, Schneck SA, Kriek E, Qi J-X, Lone T, Zhang Y-B, Snyder JA, Wells TH, Ramig LO, Thompson L, Mazziota JC, Huang SC, Grafton ST, Brooks D, Sawle G, Schroter, Ansari AA (1992) Survival of implanted fetal dopamine cells and neurologic improvement 12 and 46 months after transplantation for Parkinson's disease. N Engl J Med 327:1549-1555.

Freeman TB, Olanow CW, Hauser RA, Nauert GM, Smith DA, Borlongan CV, Sanberg PR, Holt DA, Kordower JH, Vingerhoets FJG, Snow BJ, Calne DB, Gauger LL (1995) Bilateral fetal nigral transplantation into the postcommissural putamen in Parkinson's disease. Ann Neurol 38:379-388.

Guridi J, Luquin MR, Herrero MT, Obeso JA (1993) The subthalamic nucleus: a possible target for stereotaxic surgery in Parkinson's disease. Mov Disord 8:421-429.

Hagell P, Schrag A, Piccini P, Jahanshahi M, Brown R, Rehncrona S, Widner H, Brundin P, Rothwell JC, Odin P, Wenning GK, Morrish P, Gustavii B, Björklund A, Brooks DJ, Marsden CD, Quinn NP, Lindvall O (1999) Sequential bilateral transplantation in Parkinson's disease: effects of the second graft. Brain 122:1121-1132.

Hamada I, DeLong MR (1992) Excitotoxic acid lesions of the primate subthalamic nucleus result in reduced pallidal neuronal activity during active holding. J Neurophysiol 68:1859-1866.

Hassani OK, Féger J (1999) Effects of intrasubthalamic injection of dopamine receptor agonists on subthalamic neurons in normal and 6-hydroxydopamine-lesioned rats: an electrophysiological and c-fos study. Neuroscience 92:533-543.

Hassani OK, Mouroux M, Féger J (1996) Increased subthalamic neuronal activity after nigral dopaminergic lesion independent of disinhibition via the globus pallidus. Neuroscience $72: 105-115$

Hassani OK, François C, Yelknik J, Fegér J (1997) Evidence for a dopaminergic innervation of the subthalamic nucleus in the rat. Brain Res 749:88-94.

Hauber W (1998) Blockade of subthalamic dopamine $\mathrm{D}_{1}$ receptors elicits akinesia in rats. NeuroReport 9:4115-4118.

Hauser RA, Freeman TP, Snow BJ, Nauert M, Gauger L, Kordower JH, Olanow CW (1999) Long-term evaluation of fetal nigral transplantation in Parkinson's disease. Arch Neurol 56:179-187.

Hedreen JC (1999) Tyrosine hydroxylase-immunoreactive elements in the human globus pallidus and subthalamic nucleus. J Comp Neurol 409:400-410

Henderson JM, Dunnett SB (1998) Targeting the subthalamic nucleus in the treatment of Parkinson's disease. Brain Res Bull 46:467-474.

Kordower JH, Freeman TB, Snow BJ, Vingerhoets FJG, Mufson EJ, Sanberg PR, Hauser RA, Smith DA, Nauert GM, Perl DP, Olanow CW (1995) Neuropathological evidence of graft survival and striatal reinnervation after the transplantation of fetal mesencephalic tissue in a patient with Parkinson's disease. N Engl J Med 332:1118-1124.

Kordower JH, Rosenstein JM, Collier TJ, Burke MA, Chen E-Y, Li JM, Martel L, Level AE, Mufson EJ, Freeman TB, Olanow CW (1996) Functional fetal nigral grafts in a patient with Parkinson's disease: chemoanatomic, ultrastructural, and metabolic studies. J Comp Neurol 370:203-230.

Kumar R, Lozano AM, Kim YJ, Hutchison WD, Sime E, Halket E, Lang AE (1998a) Double-blind evaluation of subthalamic nucleus deep brain stimulation in advanced Parkinson's disease. Neurology 51:850-855.

Kumar R, Lozano AM, Montgomery E, Lang AE (1998b) Pallidotomy and deep brain stimulation of the pallidum and subthalamic nucleus in advanced Parkinson's disease. Mov Disord 13:73-82.

Lavoie B, Smith Y, Parent A (1989) Dopaminergic innervation of the basal ganglia in the squirrel monkey as revealed by tyrosine hydroxylase immunohistochemistry. J Comp Neurol 289:36-52.

Lindvall O (1998) An update on fetal transplantation: the Swedish experience. Mov Disord 13[Suppl 1]:83-87.

Lindvall O, Rehncrona S, Brundin P, Gustavii B, Astedt B, Widner H, Lindholm T, Björklund A, Leenders KL, Rothwell JC (1989) Human fetal dopamine neurons grafted into the striatum in two patients with severe Parkinson's disease. A detailed account of methodology and a 6-month follow-up. Arch Neurol 46:615-631.

Lindvall O, Brundin P, Widner H, Rehncrona S, Gustavii B, Frackowiak R, Leenders KL, Sawle G, Rothwell JC, Marsden CD (1990) Grafts of fetal dopamine neurons survive and improve motor function in Parkinson's disease. Science 247:574-577.

Lindvall O, Widner H, Rehncrona S, Brundin P, Odin P, Gustavii B, Frackowiak R, Leenders KL, Sawle G, Rothwell JC, Björklund A, Marsden CD (1992) Transplantation of fetal dopamine neurons in Parkinson's disease: one-year clinical and neurophysiological observations in two patients with putaminal implants. Ann Neurol 31:155-165.

Lindvall O, Sawle, Widner H, Rothwell JC, Björklund A, Brooks D, Brundin P, Frackowiak R, Marsden CD, Odin P, Rehncrona S (1994) Evidence for long-term survival and function of dopaminergic grafts in progressive Parkinson's disease. Ann Neurol 35:172-180.

Mahalik TJ, Finger TE, Strömberg I, Olson L (1985) Substantia nigra transplants into denervated striatum of the rat: ultrastructure of graft and host interconnections. J Comp Neurol 240:60-70.

Mehta V, Spears J, Mendez I (1997) Neural transplantation in Parkinson's disease. Can J Neurol Sci 24:292-301.

Mehta V, Hong M, Spears J, Mendez I (1998) Enhancement of graft survival and sensorimotor behavioural recovery in rats undergoing transplantation with dopaminergic cells exposed to glial cell linederived neurotrophic factor. J Neurosurg 88:1088-1095.

Mendez I, Hong M (1997) Reconstruction of the striato-nigro-striatal circuitry by simultaneous double dopaminergic grafts: a tracer study using fluorogold and horseradish peroxidase. Brain Res 778:194-205.

Mendez I, Elisevich K, Flumerfelt B (1991) Dopaminergic innervation of substance P-containing striatal neurons by fetal nigral grafts: an ultrastructural double-labeling immunocytochemical study. J Comp Neurol 308:66-78.

Mendez I, Elisevich K, Flumerfelt B (1992) Substance P synaptic interactions with GABAergic and dopaminergic neurons in rat substantia nigra: an ultrastructural double-labeling immunocytochemical study. Brain Res Bull 28:557-563.

Mendez I, Sadi D, Hong M (1996) Reconstruction of the nigrostriatal pathway by simultaneous intrastriatal and intranigral dopaminergic transplants. J Neurosci 16:7216-7227.

Mendez I, Dagher A, Hong M, Hebb A, Gaudet P, Law A, Weerasinghe S, King D, Desrosiers J, Darvesh S, Acorn T, Robertson H (2000) Enhancement of survival of stored dopaminergic cells and promotion of graft survival by exposure of human fetal nigral tissue to glial cell line-derived neurotrophic factor in patients with Parkinson's disease. Report of two cases and technical considerations. J Neurosurg 92:863-869.

Mintz I, Hammond C, Féger J (1986) Excitatory effect of iontophoretically applied dopamine on identified neurons of the rat subthalamic nucleus. Brain Res 375:172-175.

Nakao N, Ogura M, Nakai K, Itakura T (1998) Intrastriatal mesencephalic grafts affect neuronal activity in basal ganglia nuclei and their target structures in a rat model of Parkinson's disease. J Neurosci 18:1806-1817.

Nikkhah G, Cunningham MG, Jödicke A, Knappe U, Björklund A (1994) Improved graft survival and striatal reinnervation by microtransplantation of fetal nigral cell suspensions in the rat Parkinson model. Brain Res 633:133-143. 
Nikkhah G, Cunningham MG, McKay R, Björklund A (1995) Dopaminergic microtransplants into the substantia nigra of neonatal rats with bilateral 6-OHDA lesions. II. Transplant-induced behavioral recovery. J Neurosci 15:3562-3570.

Nishino H (1993) Intracerebral grafting of catecholamine producing cells and reconstruction of disturbed brain function. Neurosci Res 16:157-172.

Olanow CW, Kordower JH, Freeman TB (1996) Fetal nigral transplantation as a therapy for Parkinson's disease. Trends Neurosci 19:102-109.

Olsson M, Nikkhah G, Bentlage C, Björklund A (1995) Forelimb akinesia in the rat Parkinson model: differential effects of dopamine agonists and nigral transplants as assessed by a new stepping test. J Neurosci 15:3863-3875

Piccini P, Brooks DJ, Bjorklund A, Gunn RN, Grasby PM, Rimoldi O, Brundin P, Hagell P, Rehncrona S, Widner H, Lindvall O (1999) Dopamine release from nigral transplants visualized in vivo in a Parkinson's patient. Nat Neurosci 2:1137-1140.

Remy P, Samson Y, Hantraye P, Fontaine A, Defer G, Mangin JF, Fenelon G, Geny C, Ricolfi F, Frouin V (1995) Clinical correlates of $\left[{ }^{18} \mathrm{~F}\right]$ fluorodopa uptake in five grafted parkinsonian patients. Ann Neurol 38:580-588.

Rodriguez MC, Guridi OJ, Alvarez L, Mewes K, Macias R, Vitek J, DeLong MR, Obeso JA (1998) The subthalamic nucleus and tremor in Parkinson's disease. Mov Disord 13:111-118.

Schmidt RH, Ingvar M, Lindvall O, Stenevi U, Björklund A (1982) Functional activity of substantia nigra grafts reinnervating the striatum: neurotransmitter metabolism and $\left[{ }^{14} \mathrm{C}\right] 2$-deoxy-D-glucose autoradiography. J Neurochem 38:737-748.

Schwartzman RJ, Alexander GM, Ferraro TN, Grothusen JR, Stahl SM (1988) Cerebral metabolism of parkinsonian primates 21 days after MPTP. Exp Neurol 102:307-313.

Spencer DD, Robbins RJ, Naftolin F, Marek KL, Vollmer T, Leranth C, Roth RH, Price LH, Gjedde A, Bunney BS, Sass KJ, Elsworth JD, Kier EL, Makuch R, Hoffer PB, Redmond Jr DE (1992) Unilateral trans- plantation of human ventral mesencephalic tissue into the caudate nucleus of patients with Parkinson's disease. N Engl J Med 327:1541-1548

Starr PA, Vitek JL, Bakay RAE (1998) Ablative surgery and deep brain stimulation for Parkinson's disease. Neurosurgery 43:989-1015.

Triarhou LC, Stotz EH, Low WC, Norton J, Ghetti B, Landwehrmeyer B, Palacios JM, Simon JR (1994) Studies on the striatal dopamine uptake system of weaver mutant mice and effects of ventral mesencephalic grafts. Neurochem Res 19:1349-1358.

Trugman JM (1995) D1/D2 actions of dopaminergic drugs studied with [C-14] 2-deoxyglucose autoradiography. Prog Neuropsychopharmacol Biol Psychiatry 19:795-810.

Versteeg DH, Van Der Gugten J, De Jong W, Palkovits M (1976) Regional concentrations of noradrenaline and dopamine in rat brain. Brain Res 113:563-574.

Vidakovic A, Dragasevic N, Kostic VS (1994) Hemiballism: Report of 25 cases. J Neurol Neurosurg Psychiatry 57:945-949.

Wenning GK, Odin P, Morrish P, Rehncrona S, Widner H, Brundin P, Rothwell JC, Brown R, Gustavii B, Hagell P, Jahanshahi M, Sawle G, Björklund A, Brooks DJ, Marsden CD, Quinn NP, Lindvall O (1997) Short- and long-term survival and function of unilateral intrastriatal dopaminergic grafts in Parkinson's disease. Ann Neurol 42:95-107.

Widner H, Tetrud J, Rehncrona S, Snow B, Brundin P, Gustavii B, Björklund A, Lindvall O, Langston JW (1992) Bilateral fetal mesencephalic grafting in two patients with Parkinsonism induced by 1-methyl4-phenyl-1,2,3,6-tetrahydropyridine. N Engl J Med 327:1556-1563.

Winkler C, Bentlage C, Nikkhah G, Samii M, Björklund A (1999) Intranigral transplants of GABA-rich striatal tissue induce behavioural recovery in the rat Parkinson model and promote the effects obtained by intrastriatal dopaminergic transplants. Exp Neurol 155:165-186.

Wolfson L, Brown LL, Makman M, Warner C, Dvorkin B, Katzman R (1982) Dopamine mechanisms in the subthalamic nucleus and possible relationship to hemiballismus and other movement disorders. In: Gilles de la Tourette syndrome (Freidhoff AJ, Chase TN, eds) pp 203-211. New York: Raven. 